\title{
The Trend of Average Unit Price in Taipei City
}

\author{
Hong-Yu Lin ${ }^{1} \&$ Kuentai Chen ${ }^{2}$ \\ ${ }^{1}$ Department of Business and Management, Ming Chi University of Technology, Taiwan \\ ${ }^{2}$ Department of Industrial Engineering and Management, Ming Chi University of Technology, Taiwan \\ Correspondence: Kuentai Chen, Department of Industrial Engineering and Management, Ming Chi University of \\ Technology, 84 Gungjuan Road, Taishan, New Taipei 24301, Taiwan. E-mail: kuentai@mail.mcut.edu.tw \\ Received: January 12, 2015 \\ Accepted: February 2, 2015 \\ Online Published: February 4, 2015 \\ doi:10.5430/rwe.v6n1p133 \\ URL: http://dx.doi.org/10.5430/rwe.v6n1p133
}

\begin{abstract}
The volatility of real estate prices is one of the key factors to the decision making of financial institutions, as well as to a country's economic development. Therefore how to catch the trend of this real estate price has been an important issue for Governments and financial institutions. In this study, we discuss the trend of average unit price in a capital city, in hope of establishing a decent predicting model and key factors for this price. Other than traditional statistic methods, Neural Networks (NN) and Support Vector Regression (SVR) have demonstrated their advantages in previous research, and thus are applied and compared in this study. Variables are first summarized and concluded from earlier research and then selected by stepwise procedure. The result shows that SVR outperformed NN and stepwise procedure is valid in variable selections, and the key factors are previous trading price, Money supply M2 and New House-purchasing Loans.
\end{abstract}

Keywords: average unit price, housing, prediction, neural networks, SVR, support vector regression, real estates

\section{Introduction}

The volatility of real estate prices has been an important issue for financial institutions. For financial institutions, if the price volatility of real estates can be forecasted more precisely, the risk of breach of loan contract can be reduced significantly. Moreover, the bankruptcy of Lehman Brothers in August 2007 might have some chance to be avoided. The Government also puts an eye on it and wishes to have the amplitude of price changes under control. In fact, the price volatility of real estates played an important role in formation and rupture of the Economic Bubble, and indeed affect global economics greatly (Kaashoek and Dijk, 2002) such as Taiwan in 1990 and United States in 2008. As the influence of this price volatility to financial institutions and economic development can not be overlooked, to predict the price volatility of real estates accurately and then adjust relevant policies accordingly in advance is a common research goal of Governments and financial institutions.

As the traditional predicting methods for the unit price, building statistical regression models is the most common way with acceptable results. Nevertheless, the regression models are sometimes confined by certain function and thus do not always provide desired solutions (Tay and Ho, 1992; Do and Gary, 1992). On the other hand, soft computing methods such as Neural Network (NN) and Support Vector Regression (SVR) have been demonstrated to be capable of dealing with nonlinear problems (Tsoukalas and Uhrig, 1997; Kuan and White, 1994; Lin and Lee, 1996), where strict pre-assumptions are not required. In previous researches, we can find out that various Neural Networks have become popular and useful for housing price problems with enough historical data. For instance, Do and Gary (1992) compared Neural Networks and multi-regression analysis by predicting real estate prices in United States and find out that NN outperformed Regression model with smaller mean absolute error (MAE). For their application, there are 105 samples and MAE is $6.9 \%$ for NN while MAE is $11.3 \%$ for Regression. Tay and Ho (1992) also used the same two methods for comparison and concluded that NN performed better. They had 822 training data sets and 222 testing data sets for the models predicting prices of Singapore Departments, resulted MAE 3.9\% for NN and $7.5 \%$ for regression. Furthermore, McCluskey et al. (1997) suggested NN to be a superior method as they took 416 housing prices in Northern Ireland to train NN and resulted in MAE of 7.75\%. More researches with similar conclusions can be found in McGreal et al. (1998) and Wong et al. (2001), with targets of Belfast in U.K. and Hong Kong, respectively. All these papers agreed that NN is a valid method in predicting housing prices.

Another popular algorithm proposed by Vapnik et al. (1997), namely Support Vector Regression (SVR), also 
contributed in financial applications in the past decade. SVR is constructed based on Support Vector Machine (SVM), which was proposed by Vapnik (1995). SVR minimized both empirical risk and structural risk and thus guarantees the existence of one unique optimal solution while avoiding over-fitting problems. This advantage entitles SVR the success in many applications such as identification, prediction, clustering, and so on. Putting the focus on financial fields, we can find a plenty of successful examples, such as stock prediction in U.S. (Trafalis and Ince, 2000), financial time series forecasting for Futures contract (Tay and Cao, 2001), and the mass appraisal of residential apartments (Tay and Ho, 1992).

In summary, both NN and SVR have been proven to be valid approaches in financial applications and usually out perform regression models. However, so far we found no efforts made in applying SVR to the prediction of real estate prices, especially in Taiwan. Therefore it is our research interest to find an efficient and précised method that can manage the price volatility of real estates. It is also our goal to investigate how good can SVR do in this instance. $\mathrm{NN}$ is introduced for the purpose of comparison, as both SVR and NN performed well in previous research in financial applications.

Figure 1 shows the monthly average housing prices of four major cities in Taiwan. As shown in Figure 1, for TaiChung city and Kaohsiung city the trends are flat, and for New Taipei City there is a slightly increase. It can be easily observed that there is an obvious trend for the average unit price in Taipei City, which therefore is chosen as our research target.

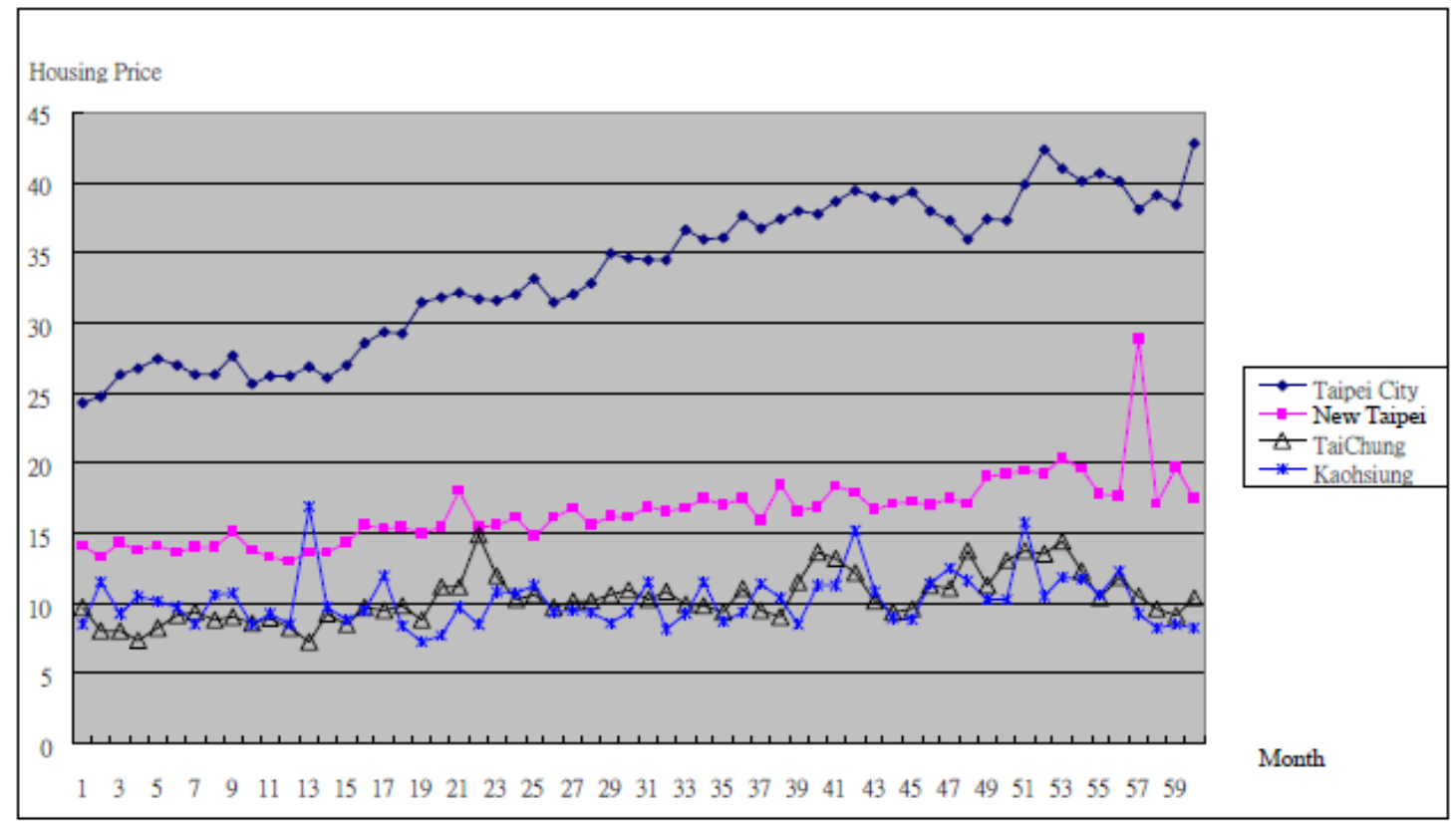

Figure 1. Trends of Taiwan's housing prices in different areas

\section{Data and Algorithms}

The data adopted in this study are mainly purchased from Taiwan's Real Estate Portal. Data are collected and averaged by month, including Taipei county, Taichung city and county, and Kaohsiung city and county. The time of collected data is from 2004/1 to 2008/12. Figure 1 shows the increasing trend of Taiwan real estate price by month, the Y-axis is the prices in $10 \mathrm{~K}$.

In this study, two popular prediction tools in soft computing, namely Back Propagation Neural Networks (BPN) and Support Vector Regression (SVR), are implemented to perform the training and predictions. Soft computing technologies have been widely implemented in many fields, including finance. Readers are referred to Chen and Lee (2006) for a BPN application and Holimchayachotikul et al. (2011) for a SVR application. Since these methods are now widely applied in many domains, only brief review and references are provided below.

\subsection{Neural Networks}

A neural network usually is equipped with three major components: architecture, learning or training algorithms, and activation functions. 
1. Architecture, which is about how the neurons are connected, how many hidden layers exist, or what the pattern of connections between the neurons is. Sometimes an extra neuron will be introduced as bias.

2. Learning or training algorithms, which is the method of determining the weights between connections. Backpropagation learning is the most popular algorithm. In general, there are three types of learning in neural networks: (1) supervised learning, when desired outputs exist; (2) unsupervised learning, when no desired outputs exist; and (3) combined supervised-unsupervised learning.

3. Activation functions. The function to determine the firing level, such as sigmoid function.

A neuron usually governs three operations:

(1) Receiving signals that are from other connected neurons, usually multiplied by weights.

(2) Aggregation and activation, that is, summing up inputs and activating the activation function.

(3) Sending out signals, which is the output of the activation function to the other connected neurons. The BPNN is a three-layer, feed-forward network with backward error propagation that learns from examples. The three layers are Input layer, Hidden layer, and Output layer as shown in Figure 2. The advantages of BPNN include the ability of training from examples, dealing with nonlinear data, error-tolerance, parallel computing, and being an universal approximator -- as long as enough data are available.

Detailed description for neural networks can be found in Hornik (1989) and a successful application of BPNN in finance can be found in Chen et al. (2009).

\subsection{Support Vector Regression}

Proposed by Vapnik (1995), Support Vector Machine is originally a classifier and is a type of supervised learning algorithm that considers both structure risk and empirical risk. SVM was first applied to pattern recognition (Schmidt, 1996), and then modified for regression estimation of signal processing (Vapnik et al., 1997). A tutorial for SVM in pattern recognition can be found in Burges (1998).

By introducing $\varepsilon$-insensitive loss function, Support Vector Machine is able to deal with nonlinear regression problems and such algorithm is thus named as Support Vector Regression Machine, usually called SVR. The structure of SVR is basically a three-layer neural network, the SVR model produced by support vector classification depends on a subset of the training data. SVR model can also cope with nonlinear data and has only a unique optimal solution with each set of kernel parameter and soft margin parameter. Therefore, other than the training process the problem becomes to search the best combination of parameters, in our study, SVR is combined with Grid algorithm for the best combination of parameters. For detailed description of SVR, the readers are referred to a tutorial in Drucker et al. (1997), and a recent review in Basak et al. (2007).

\subsection{Error Measure}

Both Mean Absolute Percentage Error (MAPE) and Coefficient of Determination $\left(R^{2}\right)$ are adopted as the indices of efficiency to compare the three methods. The equation of MAPE is as shown in the following:

$$
\text { MAPE }=\frac{\sum_{k=1}^{N}\left|\frac{d_{k}-y_{k}}{d_{k}}\right|}{N}
$$

where $d_{k}$ is the $k^{\text {th }}$ target value; $y_{k}$ is the $k^{\text {th }}$ output; and $N$ is the total number of data.

And the equation to calculate $\mathrm{R}^{2}$ is as shown in $\mathrm{EQ}(2)$.

$$
R^{2}=\frac{S S R}{S S T}=\frac{\sum_{i=1}^{N}\left(t_{i}-\bar{y}\right)^{2}}{\sum_{i=1}^{N}\left(y_{i}-\bar{y}\right)^{2}}
$$

where $y_{i}$ is the $i^{\text {th }}$ target value, $t_{i}$ is the $i^{\text {th }}$ output, and $N$ is the total number of data. 


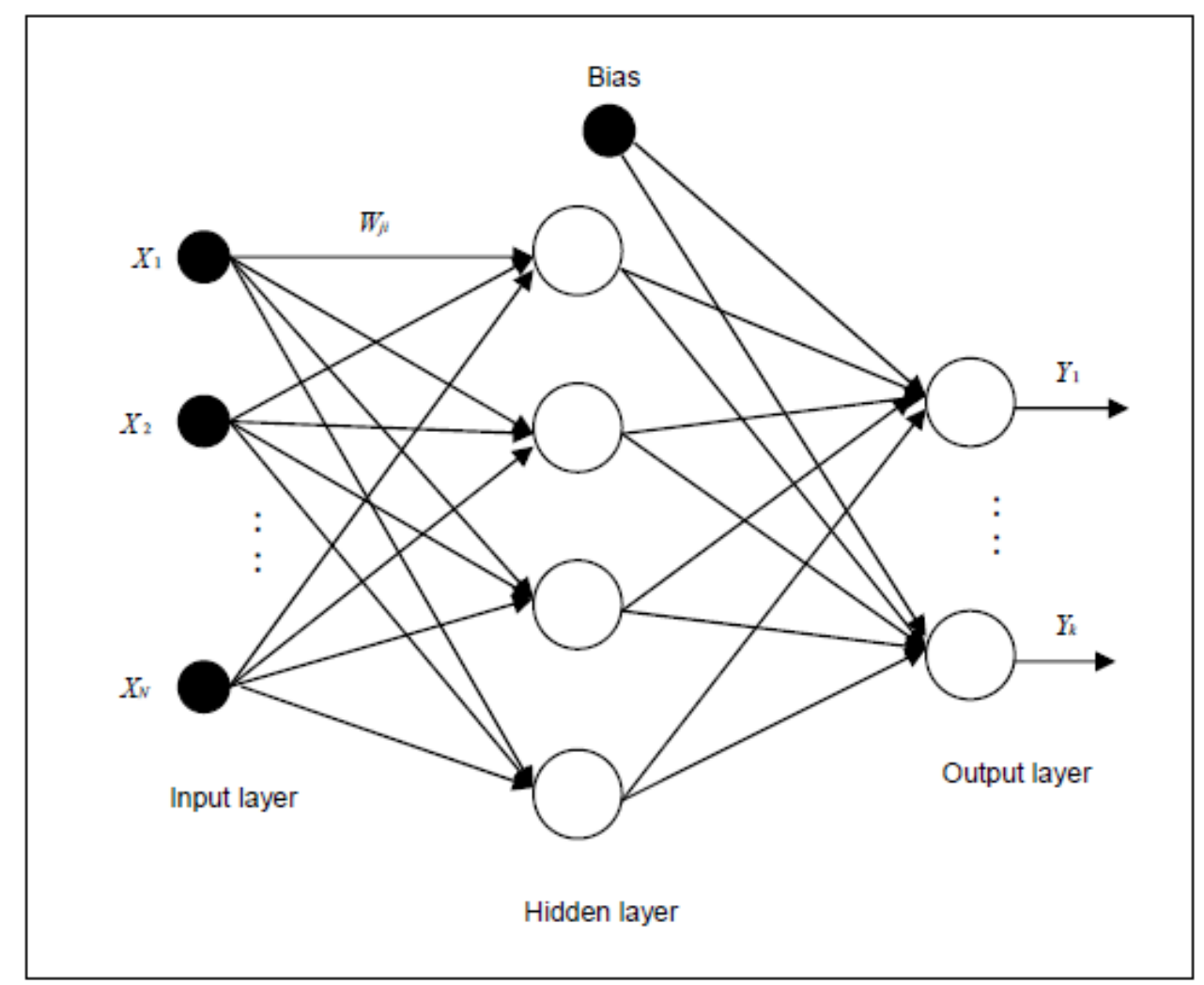

Figure 2. The structure of BPN

Original figure: Wei, H. (2004).

\section{Variables}

In practice, the previous trading price is a very important reference for the buyers. To observe the effect of the previous trading price, we built two models using this very variable as the only independent variable for both NN and SVR. With 49 training data sets and 10 testing data sets, the errors generated by these two models are shown in Table 1. From Table 1 we can see that both models are valid in predicting the prices. The resulted SVR predictions versus target values are graphed in Figure 3. The predictions seem to follow the target well, but a more precise prediction could be expected by adding more variables.

Table 1. Results for NN and SVR using $t-1$ price as the independent variable

\begin{tabular}{|c|c|c|c|c|}
\hline & \multicolumn{2}{|c|}{ Training } & \multicolumn{2}{|c|}{ Testing } \\
\hline Model & $\begin{array}{c}\text { MAPE } \\
(\%)\end{array}$ & $\mathrm{R}^{2}$ & $\begin{array}{c}\text { MAPE } \\
(\%)\end{array}$ & $\mathrm{R}^{2}$ \\
\hline $\mathrm{NN}$ & 2.03 & 0.9692 & 3.68 & 0.8879 \\
\hline SVR & 2.25 & 0.9630 & 3.63 & 0.8753 \\
\hline
\end{tabular}




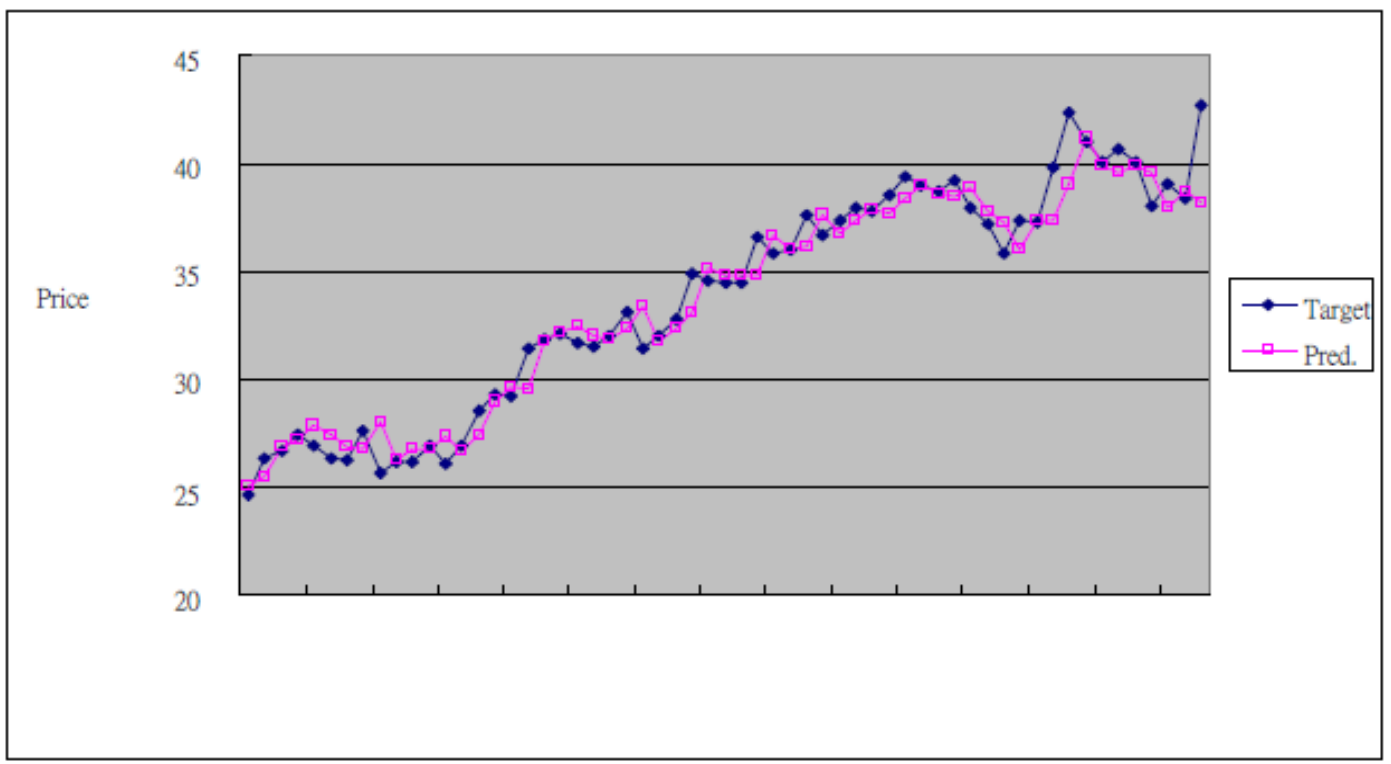

Figure 3. Targets versus predictions using SVR with t-1 price

To improve the efficiency of the model, we adopt 12 variables according to the official publication "Real Estate Cycle Indicators of Taiwan Ministry of Interior" (in Chinese). The effective variables can be classified into three categories: leading indices, simultaneous indices, and lagging indices as shown in Table 2.

As the attempt of this study is to build a model for evaluation, lagging index variables are not included in the models. In addition, due to the difficulty of data collection, Volume index of prime land and Residential use rate are not included and the Benchmarking lending rate is replaced by rediscount rate. As the rediscount rate is an important tool when Taiwan Central Bank changes its monetary policy, it is more typical in Price Discovery than other rates and therefore is used to replace Benchmarking lending rate in our research.

Table 2. Index variables

\begin{tabular}{|c|c|c|c|c|}
\hline $\begin{array}{l}\text { Real Estate aspects } \\
\text { Climate indices }\end{array}$ & Investing & Manufacturing & Trading & Using \\
\hline \multirow[t]{3}{*}{ leading indices } & Gross Domestic Product & \multirow{3}{*}{$\begin{array}{l}\text { Movement of Loans for } \\
\text { Construction }\end{array}$} & \multirow{3}{*}{\multicolumn{2}{|c|}{$\begin{array}{l}\text { Consumer Price Index, } \\
\text { CPI }\end{array}$}} \\
\hline & Money supply & & & \\
\hline & Construction stock indices & & & \\
\hline \multirow[t]{2}{*}{ simultaneous indices } & Volume index of prime land & \multirow[t]{2}{*}{ Building Permit of Residence } & $\begin{array}{l}\text { The Standard Unit Price } \\
\text { of New Cases }\end{array}$ & Residential use rate \\
\hline & Benchmarking lending rate & & $\begin{array}{l}\text { New House-purchasing } \\
\text { Loans }\end{array}$ & \\
\hline \multirow[t]{2}{*}{ lagging indices } & & $\begin{array}{l}\text { Permit for Occupancy of } \\
\text { Residence (Floor Area,m2) }\end{array}$ & $\begin{array}{l}\text { Registration of } \\
\text { Translation of Building }\end{array}$ & House Rent Price Index \\
\hline & & $\begin{array}{l}\text { Construction industry average } \\
\text { salary employees }\end{array}$ & Land Value Increment Tax & $\begin{array}{l}\text { Annual growth rate of } \\
\text { households }\end{array}$ \\
\hline
\end{tabular}

Money supply consists of three variables: M1a, M1b, and M2. In Taiwan, the measurement of Money supply includes three variables: Mla, M1b, and $M 2$. The definitions are as the following:

Mla $=$ Net currency + check deposit + current account

$M 1 b=$ Mla + current savings account

M2 =M1a + current savings account + Quasi-money, or M1b+Quasi-money. 
Although Registration of Translation of Building is classified as a lagging index in this official publication, it is included in the model as a different research by Hua and Chang (1997) suggests that the variation of amount of trading units leads to the variation of prices. As the result, thirteen variables are selected as the candidate factors of the model, namely, Gross Domestic Product(GDP), Money supply (M1a, M1b, M2), Construction Stock Indices, Movement of Loans for Construction, Consumer Price Index(CPI), Rediscount Rate(RR), Building Permit of Residence, Standard Unit Price of New Cases, New House-purchasing Loans, Registration of Translation of Building, and $t-1$ price.

\section{Analysis and Comparison}

The NN toolbox in MATLAB2008 is used for the training of $\mathrm{NN}$, the settings of the training are Levenberg-Marquarft algorithm (Trainlm); adaption function of Learngdm; hidden layer transformation function of Logsig; output function of Purelin, and maximum training epochs of 3000. For SVR, Radial basis function is adopted as the kernel function and Grid algorithm is applied for the best combination of trade-off constant $\mathrm{C}$ and free parameter $\sigma$.

To find the best combination of variables that build the model with minimal errors, both stepwise procedure and trial-and-error methods are implemented. For comparison, the variables selected by the Stepwise procedure are applied to models of both NN and SVR. On the other hand, each of NN and SVR has its own trial-and-error test. The selected variables from the stepwise procedure are as shown in Table 3. In Table 3 we can observe that the most important variables are $t-1$ price and then New House-purchasing Loans, and thereafter Money supply. For NN, the best variable combination using trial-and error method is as shown in Table 4, which includes two variables $t$-1 price and Rediscount Rate. For SVR, the best variable combination using trial-and error method is as shown in Table 5, which includes five variables, namely t-1 price, Construction Stock Indices, GDP, Money supply M2, New House-purchasing Loans. The detailed results will be provided below.

Table 3. Variables selected by stepwise procedure

\begin{tabular}{|c|c|c|c|c|c|c|c|}
\hline Variable & $C P I$ & $\begin{array}{l}\text { Money } \\
\text { supply } \\
\text { Mla }\end{array}$ & $\begin{array}{l}\text { Money } \\
\text { supply } \\
\text { M1b }\end{array}$ & $\begin{array}{l}\text { Money } \\
\text { supply M2 }\end{array}$ & $\begin{array}{l}\text { Movement of Loans } \\
\text { for Construction }\end{array}$ & $\begin{array}{l}\text { New } \\
\text { House-purchasing } \\
\text { Loans }\end{array}$ & $\begin{array}{l}-1 \\
\text { price }\end{array}$ \\
\hline 1 & & & & $\checkmark$ & & $\checkmark$ & $\checkmark$ \\
\hline 2 & & $\checkmark$ & & & $\checkmark$ & $\checkmark$ & $\checkmark$ \\
\hline 3 & $\checkmark$ & & $\checkmark$ & & $\checkmark$ & $\checkmark$ & $\checkmark$ \\
\hline
\end{tabular}

Table 4. Variables selected by trial-and-error method for NN

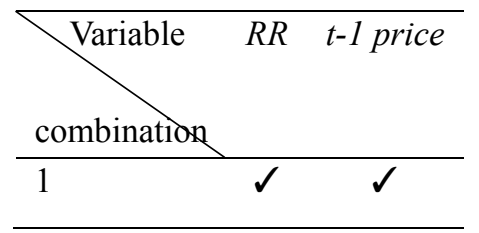

Table 5. Variables selected by trial-and-error method for SVR

\begin{tabular}{lccccc}
\hline Variable & Construction Stock Indices & GDP & Money supply M2 & New House-purchasing Loans & t-1 price \\
Combination & & & & & \\
\hline 1 & $\checkmark$ & $\checkmark$ & $\checkmark$ & $\checkmark$ & $\checkmark$ \\
\hline
\end{tabular}

By observing Table 6, we can see that the best model for NN with the smallest testing error (MAPE $=3.4554 \%$ ) is the one with 3 variables, namely $t-1$ price, New House-purchasing Loans, Money supply M2. For stepwise regression analysis, the one with the smallest training error is $\mathrm{NN}$ with 5 variables (MAPE $=1.7677 \%$ ), but its testing result (MAPE $=4.9547 \%)$ is the worse among these three models. If we include the model with trial-and-error, we see that the model with the smallest training error is $\mathrm{NN}$ with 2 variables using trial-and-error method (MAPE=1.1196\%), but 
the testing result is not as good (MAPE $=4.4341 \%$ ). This suggests that there is a chance of over-fitting. Also, only this three-variable model (testing MAPE $=3.4554 \%$ ) performed better than $\mathrm{NN}$ with only one variable $t-1$ price (testing MAPE $=3.6812 \%$ ).

By observing Table 7, we can see that the best model for SVR with the smallest testing error (MAPE $=2.7436 \%$ ) is the one with 3 variables, namely $t-1$ price, New House-purchasing Loans, Money supply M2. For stepwise regression analysis, the one with the smallest training error is $\mathrm{NN}$ with 5 variables (MAPE=1.6034), but its testing result (MAPE $=5.9384 \%)$ is the worse among all models. This suggests that there is a chance of over-fitting. If we include the model with trial-and-error, the same conclusion can be made. All the SVR models but SVR with 5 variables performed better than SVR with only one variable $t$-1 price (testing MAPE=3.6387\%).

In summary, we can conclude that stepwise regression analysis dose well in variable selection of housing price model. This implies there is a good linear relation between independent variables and dependent variable. It makes sense since $t$ - 1 price is included in the model and is always first selected. We can also find that besides $t-1$ price, New House-purchasing Loans and Money supply are commonly selected by both NN and SVR models, which gives us the confidence that they are important variables in predicting housing prices.

Table 6. Training and testing results of NN

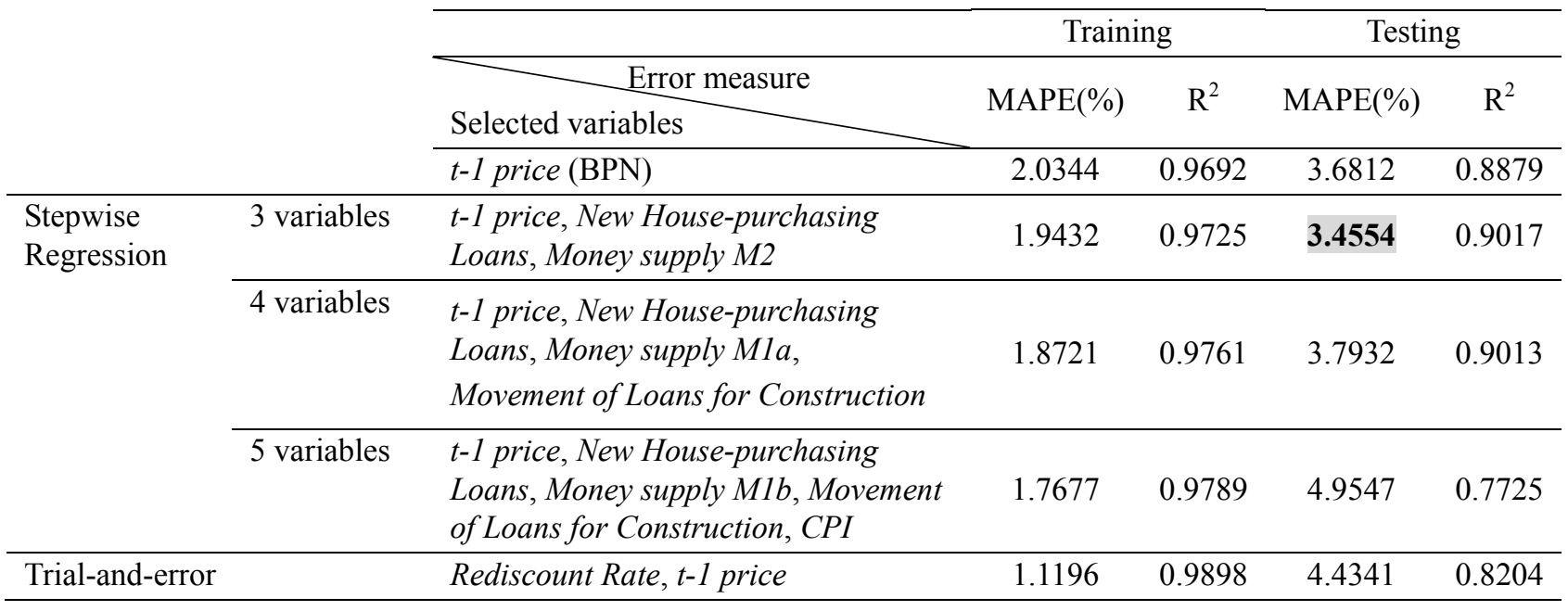

Table 7. Training and testing results of SVR

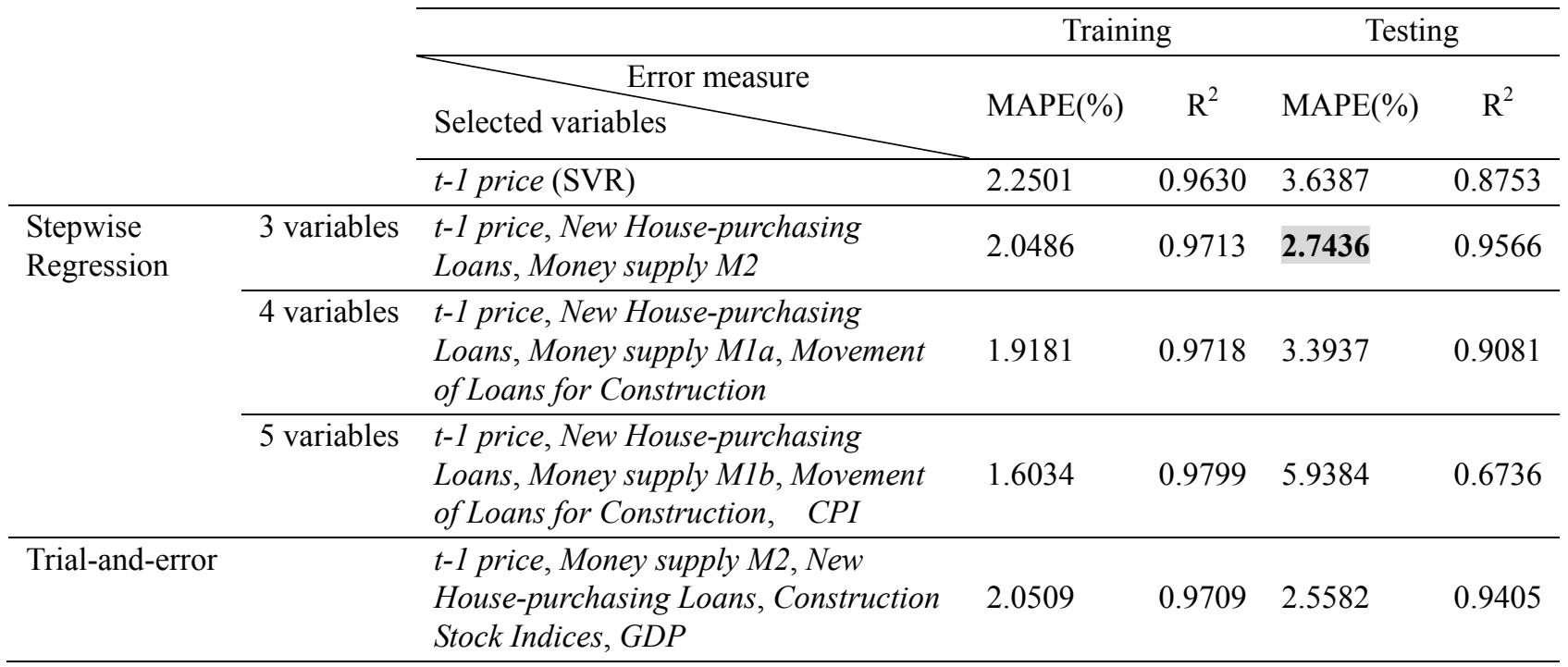

The resulted best variable combination and errors for NN and SVR are as shown in Table 8. In Table 8, we can observe that by adding two variables (Money Supply M2 and New House-Purchasing Loans) to NN model, there is 
only slight improvement (testing error MAPE $=3.46 \%$ ) than using only $t-1$ price as the input variable (testing error MAPE $=3.68 \%$ ). On the other hand, adding the same two variables to SVR model leads a significant improvement (testing error MAPE $=2.74 \%$ ) than using only $t-1$ price as the input variable (testing error MAPE $=3.63 \%$ ). The same improvement appeared at the $\mathrm{R}^{2}$, a significant increase from 0.8753 to 0.9566 . Note that Money Supply M2 and New House-Purchasing Loans are selected by stepwise procedure for both NN and SVR. The result of SVR predictions versus target prices is graphed in Figure 4, which shows our best model: SVR with three variables selected by stepwise procedure. From Table 6 8, Figure 3 and Figure 4, we can see that SVR outperformed NN when using both one and three variables. Adding more variables neither significantly improved the NN model, nor the SVR model.

To further observe the robustness of NN and SVR, we collected and listed their maximum and minimum MAPEs in Table 9. In Table 9 we can see that SVR has a smaller variation in MAPE. That is, SVR performed better in this application not only in precision, but also in robustness.

Table 8. Selected variables and the best result of NN and SVR

\begin{tabular}{lccccc}
\hline Variables selected & Method & \multicolumn{2}{c}{ Training } & \multicolumn{2}{c}{ Testing } \\
\hline$t-1$ price & & MAPE $(\%)$ & $\mathrm{R}^{2}$ & MAPE $(\%)$ & $\mathrm{R}^{2}$ \\
& $\mathrm{NN}$ & 2.03 & 0.9692 & 3.68 & 0.8879 \\
\cline { 2 - 6 } & $\mathrm{SVR}$ & 2.25 & 0.9630 & 3.63 & 0.8753 \\
\hline$t-1$ price, & $\mathrm{NN}$ & 1.94 & 0.9725 & $\mathbf{3 . 4 6}$ & 0.9017 \\
$\begin{array}{l}\text { Money SupplyM2, } \\
\text { New House-purchasing Loans }\end{array}$ & $\mathrm{SVR}$ & 2.05 & 0.9713 & $\mathbf{2 . 7 4}$ & 0.9566 \\
\hline
\end{tabular}

Table 9. Ranges of testing MAPEs of NN and SVR

\begin{tabular}{ccccccc}
\hline & \multicolumn{3}{c}{ Testing } \\
\hline & $\begin{array}{c}\text { MAPE } \\
(\%)\end{array}$ & $\mathrm{R}^{2}$ & $\begin{array}{c}\text { MAPE } \\
(\%)\end{array}$ & $\mathrm{R}^{2}$ & Max MAPE & Min MAPE \\
& $(\%)$ & $(\%)$ \\
\hline NN with 3 variables & 1.94 & 0.9725 & 3.46 & 0.9017 & 9.38 & 0.14 \\
\hline SVR with 3 variable & 2.05 & 0.9710 & 2.74 & 0.9566 & 5.44 & 0.12 \\
\hline
\end{tabular}

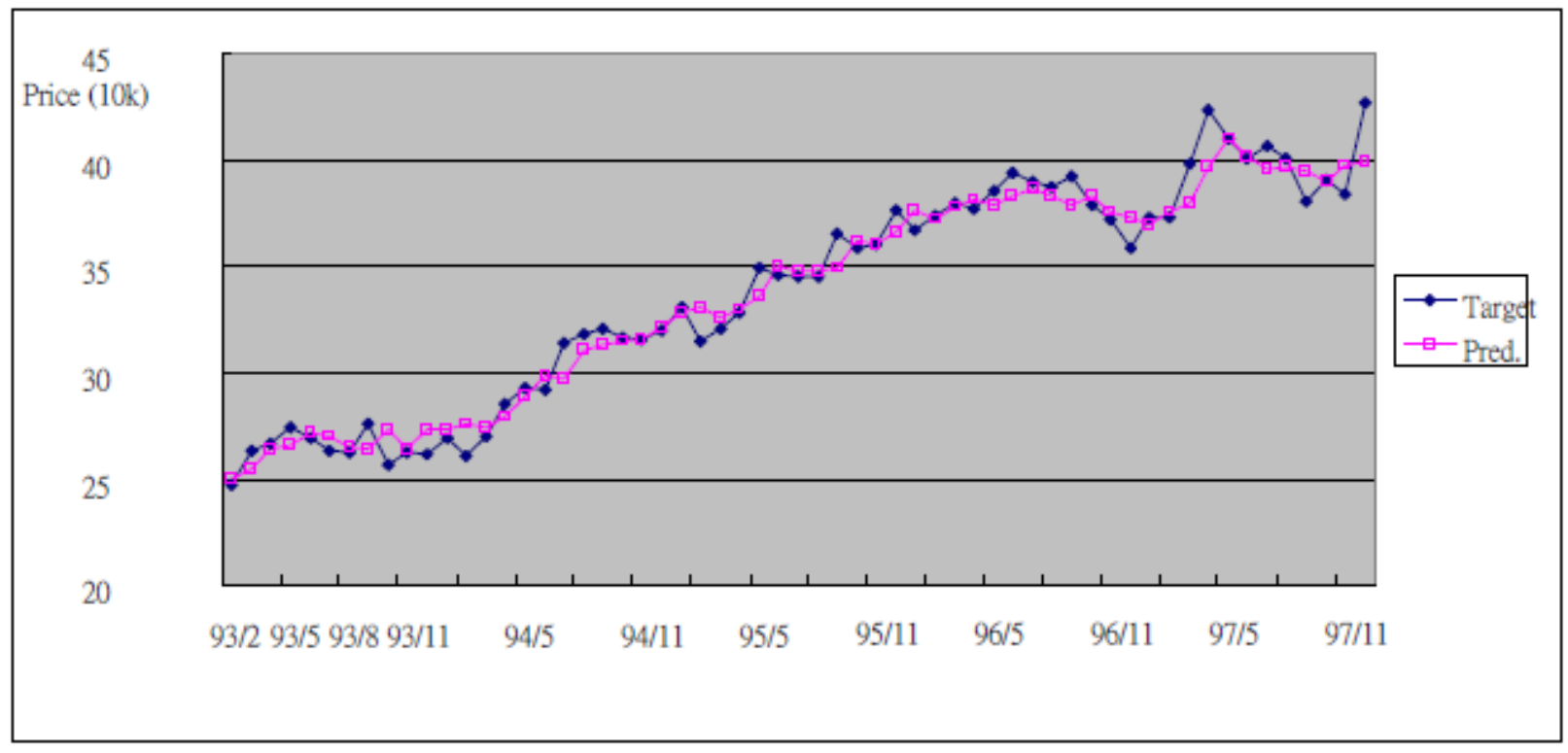

Figure 4. Prediction of SVR with three variables selected by stepwise procedure 
Finally, we will discuss the three variables, namely t-1 price, Money Supply M2, and New House-Purchasing Loans that are commonly selected for both NN and SVR models. The selection of variable $t-1$ price is of no doubt, since the previous trading price is the most important reference for buyers. Indeed, $t-1$ price contributes to both model the most with R2 of greater than 0.8753. Another selected variable, Money Supply M2, is the index for Central Bank of ROC (Taiwan) to monitor the amount of currency. It is also a key index to see if the funds in the market are sufficient. Hence it makes sense for Money Supply M2 to be selected since the more money the buyers have, the easier the deal can be closed. The third selected variable, New House-Purchasing Loans, is usually close related to the lending rate and Loan-to-Value (LTV). However, as the leading index of all rates, the rediscount rate is not selected for the models. This implies that LTV is concerned more by the buyers rather than the lending rate.

Note that the GDP is not selected as an important variable. In summary, we think it suggests that the average unit price in Taipei is more related to fund and investment, but not the product itself. This in some degree agrees with the irrational increase of unit price in Taipei City.

\section{Conclusion}

The volatility of real estate prices is one of the key factors to the decision making of financial institutions, as well as to a country's economic development. Hence its trend prediction has been important to the Governments and financial institutions. Traditional time series method is a general way to approach this prediction, yet the results sometimes are not satisfactory. In our study, we identified key factors for the prediction models other than previous price and tested Neural Networks and Support Vector Regression. The result shows that SVR with stepwise procedure is an efficient method in the prediction of average unit price in Taipei City, it outperformed NN. The identified key factors are previous trading price, Money supply M2 and New House-purchasing Loans with a $\mathrm{R}^{2}$ of 0.9566 and MAPE of $2.74 \%$, which is much better than only using time series method.

\section{References}

Basak, D., Pal, S., \& Patranabis, D. C. (2007, October). Support Vector Regression. Neural Information Processing-Letters and Reviews, 11(10), 203-224.

Burges, C.J.C. (1998). A tutorial on support vector machines for pattern recognition. Knowledge Discovery and Data Mining, 2(2), 121-167.

Chen, K.T., \& Lee, E. S. (2006, August). Apply Fuzzy Adaptive Networks to credit rating. WSEAS Transactions on Business and Economics, 3(8), 597-604.

Chen, K.T., Lin, H.-Y., \& Huang, T.-C. (2009, September). The Prediction of Taiwan 10-Year Government Bond Yield. WSEAS Transactions on Systems, 8(9), 1051-1060.

Do, Q., \& Gary, G. (1992). A Neural Network Approach to Residential Property Appraisal. Real Estate Appraiser, $58(3), 38-45$.

Drucker, H., Burges, C.J.C., Kaufman, L., Smola, A., \& Vapnik, V. (1997). Support vector regression machines. In M. Mozer, M. Jordan, and T. Petsche (Eds.), Advances in Neural Information Processing Systems (Vol. 9, pp.155-161). Cambridge, MA, MIT Press.

Holimchayachotikul, P., Leksakul, K., \& Guizzi, G. (2011, Jan.). Robust Design for Etching Process Parameters of Hard Disk Drive Slider Fabrication Using Data Mining and Multi Response Optimization. WSEAS Transactions on Systems and Control, 6(1), 15-24.

Hornik, K., Stinchcombe, M., \& White, H. (1989). Multilayer feedforward networks are universal approximators. Neural Networks, 2(5), 359-366. http://dx.doi.org/10.1016/0893-6080(89)90020-8

Hua, C.-C., \& Chang, C.-O. (1997). Housing Fluctuation Patterns between Transaction Price a Volume. Journal of Housing Study, 5, 1-15.

Kaashoek, J. F., \& Dijk, K. H. V. (2002). Neural Network Pruning Applied to Real Exchange Rate Analysis. Journal of Forecasting, 21(8), 559-577. http://dx.doi.org/10.1002/for.835

Kuan, C.M., \& White, H. (1994). Artificial Neural Networks: An Econometric Perspective. Econometric Reviews, 13(1), 1-91. http://dx.doi.org/10.1080/07474939408800273

Lin, C. T., \& Lee, C. S. G. (1996). Neural Fuzzy Systems: a neuro-fuzzy synergism to intelligent systems. New Jersey: Prentice Hall.

McCluskey, W. J., Dyson, K., McFall, D., \& Anand, S. (1997). The Mass Appraisal of Residential Property in 
Northern Ireland. In McCluskey, W. J. and A.S. Adair (Eds.), Computer Assisted Mass Appraisal: an international review (Vol. 3, pp.59-77). Aldershot: Ashgate.

McGreal, S., Adair, A., McBurney, D., \& Patterson, D. (1998). Neural Networks: the Prediction of Residential Values. Journal of Property Valuation and Investment, 16(1), 57-70. http://dx.doi.org/10.1108/14635789810205128

Tay, D. P. H., \& Ho. D. K. H. (1992). Artificial Intelligence and the Mass Appraisal of Residential Apartments. Journal of Property Valuation and Investment, 10(2), 520-540. http://dx.doi.org/10.1108/14635789210031181

Tay, F. E., \& Cao, H. L. (2001). Application of support vector machines in financial time series forecasting. Omega, 29(4), 309-317. http://dx.doi.org/10.1016/S0305-0483(01)00026-3

Trafalis, T. B., \& Ince, H. (2000). Support Vector Machine for Regression and Applications to Financial Forecasting. Proceedings of the IEEE-INNS-ENNS International Joint Conference on Neural Networks (IJCNN'00), 6, pp.6348-6353.

Tsoukalas, L. H., \& Uhrig, R. E. (1997). Fuzzy and Neural Approaches in Engineering. New York: Wiley and Sons.

Vapnik, V. N. (1995). The nature of statistical learning theory. New York: Springer. http://dx.doi.org/10.1007/978-1-4757-2440-0

Vapnik, V. N., Golowich, S., \& Smola, A. (1997). Support vector method for function approximation, regression estimation, and signal processing. In Mozer, M., M. Jordan and T. Petsche (Eds.), Advances in Neural Information Processing Systems (Vol. 9, pp.281-287). Cambridge, MA: MIT Press.

Wong, K., So, AT. P., \& Hung, Y .C. (2001). Neural Network vs. Hedonic Price Model: Appraisal of High-density Condominiums. In Wang, Ko, \& Wolverton, M. L. (Eds.), Real Estate Valuation Theory (pp.181-198). Boston, Mass.: Kluwer Academic. 